\title{
Management of Endodontic Instrument Separation in Primary Teeth
}

\author{
Morankar Rahul ${ }^{1}$, Aditi Kapur ${ }^{2}$, Krishan Gauba $^{3}$, Ashima Goyal $^{4}$
}

\begin{abstract}
Background: Endodontic instrumentation is challenging in primary teeth due to narrow and curved roots that are under the influence of the physiological resorption process. Instrument separation in primary tooth root canal can have an adverse effect on erupting succedaneous teeth due to the persistence of infection and the risk of getting embedded into bone following root resorption.

Case description: This paper comprised of a series of four cases with endodontic instrument separation at coronal third, middle third, apical third, and beyond apex in the root canal of primary teeth. All the cases were managed successfully using different strategies that include instrument retrieval, obturation and close periodic follow-ups, and the extraction of the involved tooth.

Conclusion: Several factors determine the fate of the primary tooth with a separated instrument. Different management strategies can be tried considering the benefit vs risk in preserving the tooth.

Keywords: Endodontic instrumentation, Instrument fracture, Management, Primary teeth.

Journal of South Asian Association of Pediatric Dentistry (2020): 10.5005/jp-journals-10077-3039
\end{abstract}

\section{INTRODUCTION}

Prevention of premature loss of primary teeth is important to preserve arch space, prevent aberrant tongue habits, speech problems, maintain esthetic, and allow normal eruption of succedaneous teeth., ${ }^{1,2}$ The majority of cases that report with carious symptomatic primary molar are generally diagnosed with irreversible pulpitis or pulp necrosis and often require pulpectomy for their management. ${ }^{3}$ Separation of endodontic instrument is an unexpected complication that can occur during root canal instrumentation and its prevalence is not known. It is a common belief among the dental professionals that rotary nickel-titanium (NiTi) instruments separate more frequently than stainless steel hand instruments. However, literature revealed that in permanent teeth, the reported prevalence of separated endodontic manual instruments is in the range of $0.7-7.4 \%$, whereas for rotary $\mathrm{NiTi}$ instruments, it is approximately $0.4-5 \% .{ }^{4-6}$ Operator-related factors such as proficiency with the instruments and decision on the number of times an endodontic instrument can be used before replacement may help to explain the variation in the prevalence of instrument separation. ${ }^{7,8} \mathrm{~A}$ randomized clinical trial comparing the efficacy of manual and rotary instruments for root canal preparation during pulpectomy in primary molars has found instrument separation in two cases with rotary files and in none with manual files in a total sample of 60 teeth. ${ }^{9}$ There is a scarcity of literature regarding the successful retrieval of the separated endodontic instrument in primary teeth. Moreover, to the best of our knowledge, there exists no information regarding the use of other management methods. This paper describes the management strategies for endodontic instrument separation in a root canal of primary teeth with emphasis on factors requiring consideration in different clinical situations. Parental consent was obtained before the commencement of treatment in each case and was explained about the advantages and complications of treatment rendered.
${ }^{1}$ Division of Pedodontics and Preventive Dentistry, Centre for Dental Education and Research, All India Institute of Medical Sciences, New Delhi, India

${ }^{2-4}$ Unit of Pedodontics and Preventive Dentistry, Oral Health Sciences Centre, Postgraduate Institution of Medical Education and Research, Chandigarh, India

Corresponding Author: Aditi Kapur, Unit of Pedodontics and Preventive Dentistry, Oral Health Sciences Centre, Postgraduate Institution of Medical Education and Research, Chandigarh, India, Phone: +91 9815966348, e-mail: draditikmalhotra@gmail.com

How to cite this article: Rahul M, Kapur A, Gauba K, et al. Management of Endodontic Instrument Separation in Primary Teeth. J South Asian Assoc Pediatr Dent 2020;3(1):34-38.

Source of support: Nil

Conflict of interest: None

\section{Case Description}

\section{Case 1}

A 6-year-old male child reported with the chief complaint of spontaneous toothache in mandibular left second primary molar [Federation Dentaire Internationale (FDI) notation 75] since few days. It has aggravated following dental treatment at a private dental clinic. Clinical examination revealed an underprepared access cavity with 75 and incomplete caries removal, which was sealed with glass ionomer cement. An intraoral periapical radiograph revealed a separated instrument of about 6-7 $\mathrm{mm}$ size in the distal root (Fig. 1A). The separated instrument was lodged firmly in distobuccal root canal $2-3 \mathrm{~mm}$ below the cementoenamel junction. The instrument was bypassed successfully with no. 15 and no. $20 \mathrm{H}$-files (Mani, Inc., Japan), but attempts for its retrieval were not successful. Gates-Glidden (GG) drills no. $2(0.7 \mathrm{~mm})$ and no. 3 $(0.9 \mathrm{~mm})$ (Mani, Inc.) were used to drill around the instrument, after which it was retrieved successfully using no. $25 \mathrm{H}$-file (Mani, Inc.)

() The Author(s). 2020 Open Access This article is distributed under the terms of the Creative Commons Attribution 4.0 International License (https://creativecommons. org/licenses/by-nc/4.0/), which permits unrestricted use, distribution, and non-commercial reproduction in any medium, provided you give appropriate credit to the original author(s) and the source, provide a link to the Creative Commons license, and indicate if changes were made. The Creative Commons Public Domain Dedication waiver (http://creativecommons.org/publicdomain/zero/1.0/) applies to the data made available in this article, unless otherwise stated. 

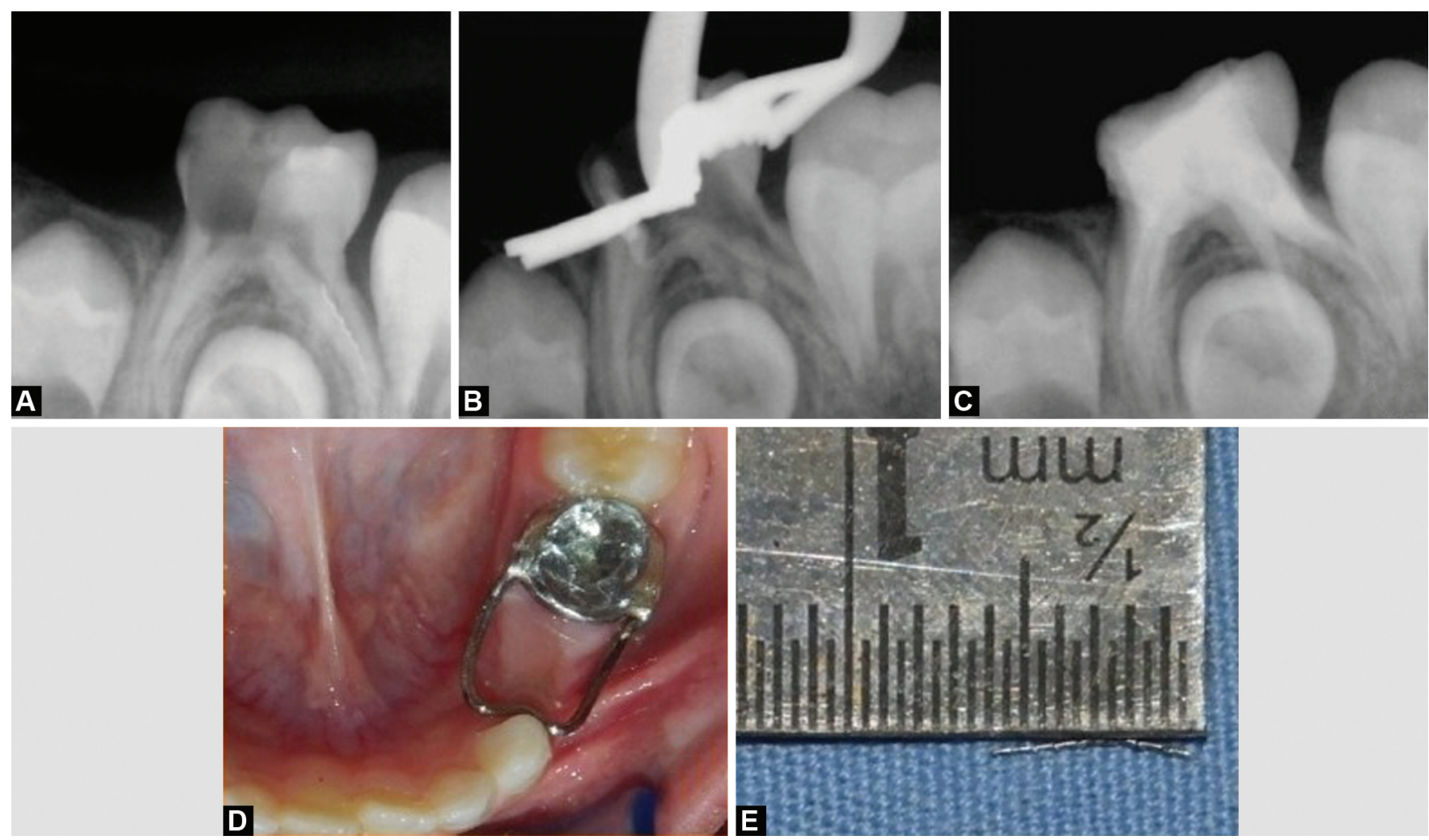

Figs 1 A to E: (A) Separated instrument in distal root; (B) After retrieval of separated instrument; (C) Post-obturation radiograph; (D) Crown and loop space maintainer; (E) Separated instrument after retrieval

(Fig. 1B). All the canals were instrumented till size $30 \mathrm{k}$-file (Mani, Inc.) followed by obturation with metapex (Meta Biomed Co. Ltd., Korea) and restoration with glass ionomer cement (GC Gold Label Universal Restorative, Japan) (Fig. 1C). It was followed by placement of a crown and loop space maintainer for missing 74 (Fig. 1D). The instrument retrieved was a manual reamer measuring $6 \mathrm{~mm}$ in length (Fig. 1E). The patient was asymptomatic since then and is under regular follow-up.

\section{Case 2}

A 5-year-old female child reported with the chief complaint of spontaneous toothache in mandibular left second primary molar (FDI notation 75). Clinical examination revealed deep occlusal caries with fractured lingual wall and pain on percussion. An intraoral periapical radiograph revealed caries involving pulp without any furcation or periapical area of rarefaction. Based on the history of clinical symptoms, a diagnosis of chronic irreversible pulpitis was made, and pulpectomy was planned. All the canals were enlarged using hyflex-control memory NiTi rotary files (Coltène Whaldent, Inc., USA) with a $4 \%$ taper operating at $500 \mathrm{rpm}$ with minimum torque setting. An orifice opener [ $(08 / 25,19 \mathrm{~mm})$ of $8 \%$ taper, size 25 , length $19 \mathrm{~mm}$ ] and nos. 04/20 file was used for instrumentation of root canal. This was followed by file nos. 04/25 which got separated in the distobuccal root canal. The radiograph confirmed a separated instrument of length $3-4 \mathrm{~mm}$ in the middle third of the root canal (Fig. 2A). The instrument was bypassed with no. 15 k-file but could not get retrieved. As instrument separation had occurred with $04 / 25$ file, the involved root canal was sufficiently debrided before separation with no. 08/25 and 04/25 files, and the level of instrument separation was at the mid-root region, so it was decided to obturate and seal this tooth with periodic follow-ups, instead of immediate extraction. All other canals were enlarged till size $04 / 30$ in the sequential manner followed by obturation using metapex (Meta Biomed Co. Ltd.) and placement of stainless steel crown (Unitek Crowns, 3 ESPE, United States) (Fig. 2B). The patient was followed up periodically for clinical symptoms, resorption of roots, development of the underlying premolar, and was found asymptomatic for 3 years. Although the patient was continued to be clinically asymptomatic, a furcation, as well as periapical radiolucency, was evident with pathological resorption of the mesial root (Fig. 2C). However, no signs of resorption were evident with distal root in which the instrument was separated. Succedaneous developing premolar has drifted distally away from the radiolucent area. The radiographic examination of contralateral mandibular second primary molar (85) showed an erupting succedaneous premolar with a normal path of eruption (Fig. 2D). Therefore, to allow normal eruption of underlying premolar, it was decided to extract 75 followed by placement of a space maintainer. An intact distal root of 75 with an instrument lodged in it was evident in extracted tooth (Fig. 2E). Furthermore, the radiograph of the extraction socket confirmed the successful retrieval of the separated instrument along with extracted tooth (Fig. $2 \mathrm{~F}$ ). Band and loop space maintainer was placed to prevent space loss (Fig. 2G). A 6-month follow-up radiograph revealed a normally developing premolar (Fig. 2H).

\section{Case 3}

A 5-year-old female child has complaint of mild intermittent pain with primary mandibular left first molar (FDI notation 74). She had undergone pulpectomy treatment for the same during which an instrument separation has occurred in the mesiobuccal root canal 

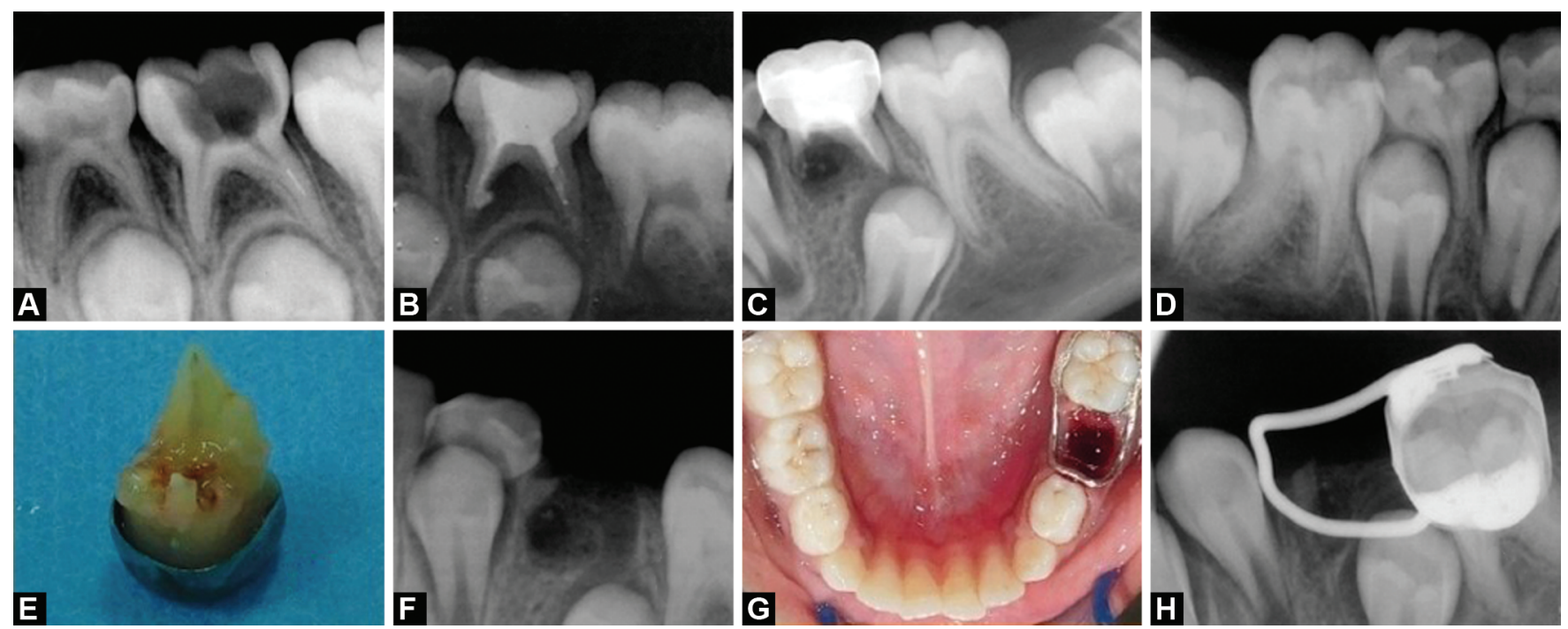

Figs $2 \mathrm{~A}$ to $\mathrm{H}$ : (A) Separated rotary instrument in distal root; (B) Post-obturation radiograph; (C) Thirty-six months follow-up radiograph; (D) Contralateral tooth after 36 months; (E) Extracted tooth with lodged instrument; (F) Post-extraction radiograph; (G) Band and loop space maintainer; (H) Six months post-extraction
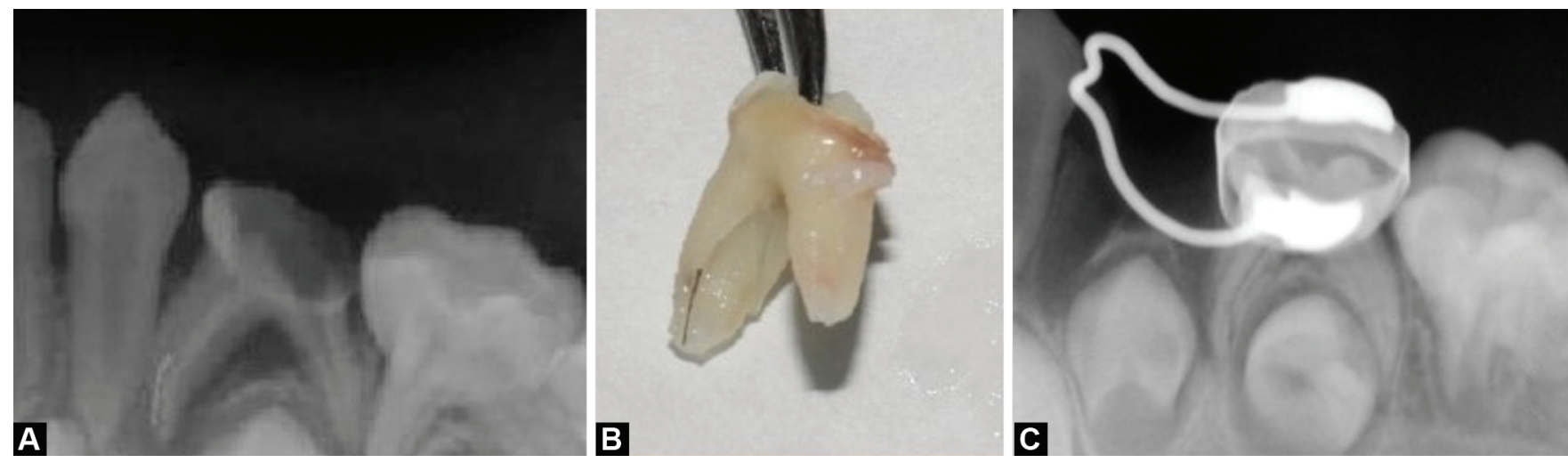

Figs 3 A to C: (A) Separated instrument in apical third of mesial root with 74; (B) Extracted tooth with lodged instrument; (C) Band and loop space maintainer

by a resident doctor. A radiograph revealed a separated instrument of about $4 \mathrm{~mm}$ in size lodged in the apical third but within the confines of the mesial root (Fig. 3A). An attempt was made for its retrieval but was unsuccessful. The extraction of the involved tooth was carried out under local anesthesia (Lox 2\%; Neon Laboratories) (Fig. 3B) followed by a band and loop space maintainer (Fig. 3C).

\section{Case 4}

A 7-year-old male child reported with a chief complaint of mild intermittent pain on food lodgment with the primary mandibular right first and second molars (FDI notations 84 and 85). The patient had a history of dental treatment at a private dental clinic few months back which he did not continue further. Clinical examination revealed glass ionomer restoration with 85 and proximal caries with 84 leading to food lodgment. An intraoral periapical radiograph with 85 revealed empty root canals with a separated instrument of about 3-4 $\mathrm{mm}$ size beyond the apex of mesial root close to the developing succedaneous premolar (Fig. 4A). Immediate extraction of involved tooth was carried out under local anesthesia (Lox 2\%; Neon laboratories, Mumbai, India) followed by a gentle curettage without damaging the underlying developing tooth bud (Fig. 4B).
The post-extraction radiograph has confirmed the successful retrieval of the separated instrument (Fig. 4C).

\section{Discussion}

Separated endodontic instrument can have adverse effects on erupting succedaneous tooth due to persistence of infection and risk of getting embedded into bone following root resorption, making extraction of affected tooth a preferred choice of treatment.10,11

Improper technique and overuse are the most common reasons of instrument separation in the root canal. However, the mechanism of instrument separation is different in stainless steel and NiTi rotary files. Stainless steel files usually separate/ fracture due to the excessive amounts of torque and overuse or the preexisting distortion of the instrument, whereas in $\mathrm{NiTi}$ rotary files, it is a combined result of torsional stress and cyclic fatigue. ${ }^{12-14}$ Numerous factors have been implicated in the fracture of endodontic instruments including operator skill/experience, instrumentation technique, dynamics of instrument use, number of uses, instrument design, anatomic configuration of the canals, metallurgy, and number of sterilization cycles. ${ }^{15,16}$ 

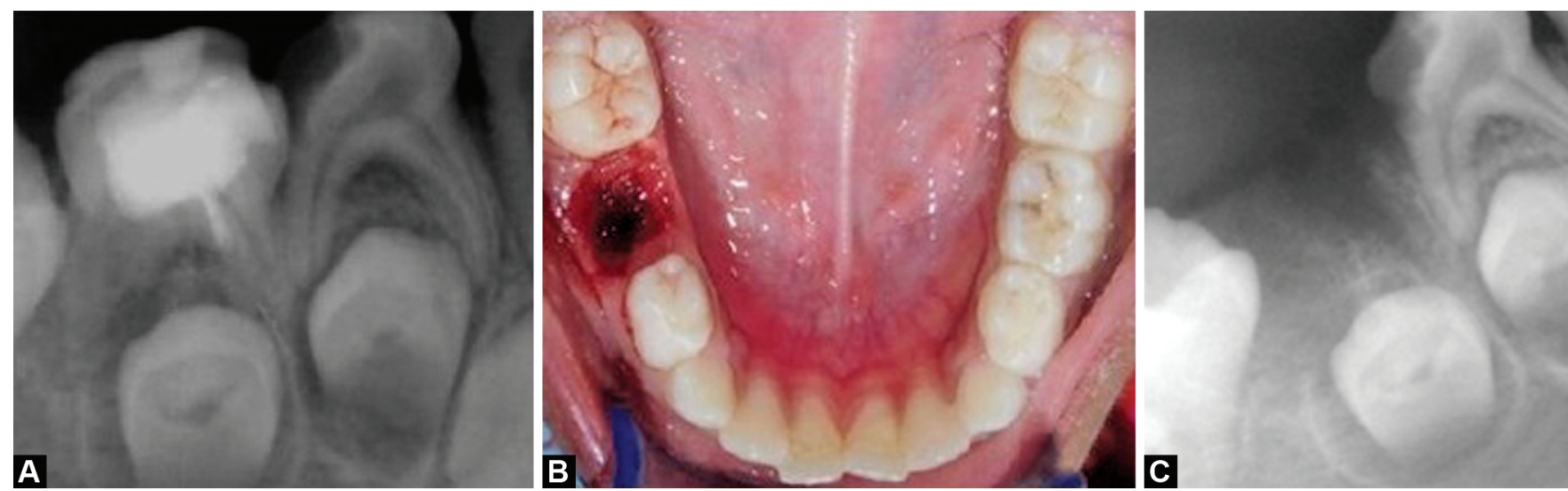

Figs 4A to C: (A) Separated instrument beyond apex of mesial root; (B) Extraction of involved tooth; (C) Post-extraction radiograph after instrument retrieval

Instrument separation is not an uncommon complication which takes place while instrumentation of root canals during pulp therapy. Therapeutic options for the management of separated endodontic instruments include no intervention, nonsurgical (orthograde, conservative) management, surgical management, and tooth extraction. ${ }^{17}$ Use of Stieglitz pliers, ultrasonic scaler, Masserann technique, Endo extractor, and Cavi-Endo ultrasonic instruments are some of the methods popular for retrieval of a separated endodontic instrument in the permanent tooth. ${ }^{18}$

The location of the separated endodontic instrument in the root canal is the most crucial factor that determines the treatment choice for a primary tooth with a separated instrument. An attempt should be made to retrieve a separated instrument whenever it is within the canal like it was attempted in three of our cases (cases 1, 2, and 3). In case 4, the instrument was beyond the apex, and therefore, attempt for its retrieval was not made to avoid any trauma to the underlying developing premolar. Furthermore, in cases 1 and 2, instrument has separated in the coronal and middle third of the root canal, respectively. In case 1 , a 6-mm-long manual reamer was retrieved successfully with the use of GG drill using a manual file and copious irrigation, which is the most desired treatment outcome. In case 2, the retrieval of separated rotary file lodged in the middle third of the root canal was unsuccessful in spite of multiple attempts. It was, therefore, managed with routine obturation followed by restoration to maintain the tooth in its physiological functional state. It was kept under close periodic follow-up, at least every 3 months. This treatment option should be encouraged where it is possible to follow up the patient clinically and radiographically at close periodic intervals as there is the possibility of instrument escaping into bone due to physiological root resorption.

In cases 3 and 4, an instrument has separated in the apical root portion. In case 3 , it was within the root canal, and thus, an attempt was made for its retrieval, which was unsuccessful. It was, therefore, extracted to prevent the fractured instrument from getting exposed in the bone following resorption, as there is no accurate and consistent established age for initiation of resorption in primary teeth known per se. In case 4, an immediate extraction of involved tooth was carried out as the separated instrument was beyond the apex of the primary tooth root.
Age of the child, clinical signs and symptoms, and amount of root resorption are the factors which can also influence the management of separated instrument in primary teeth. Moreover, if an instrument has separated after initial cleaning and shaping of root canal, maintaining a tooth is not a problem as clinical signs and symptoms are not anticipated and the good prognosis is expected. However, if an instrument has separated early during the initial cleaning and shaping of the root canal, clinical symptoms may compromise the prognosis. Therefore, these factors should be kept in mind while planning a suitable management strategy to avoid or at least reduce the burden of extraction and wear of space maintainer for longer period (Flowchart 1). More emphasis should be given toward the preservation of teeth in younger children considering the consequences of early tooth loss compared with their older counterparts.

\section{Conclusion}

The management and prognosis of a primary tooth with a separated instrument is dependent on the level of instrument fracture within the root, age of the child, root resorption, and clinical signs and symptoms of the involved tooth. Different management approaches can be tried depending on clinical situations keeping in mind benefits vs risks in preserving the tooth.

\section{Informed Consent}

Informed consent was obtained from all individual participants included in the study.

\section{AUthORSHIP}

This manuscript represents valid work and that neither this manuscript nor one with substantially similar content under the present authorship has been published or is being considered for publication elsewhere and the authorship of this article will not be contested by anyone whose name(s) is/are not listed here, and that the order of authorship as placed in the manuscript is final and accepted by the co-authors. These declarations also represent the authorship which is signed by all the authors in the order in which they are mentioned in the original manuscript. 
Flowchart 1: Management strategies for endodontic instrument separation in primary teeth

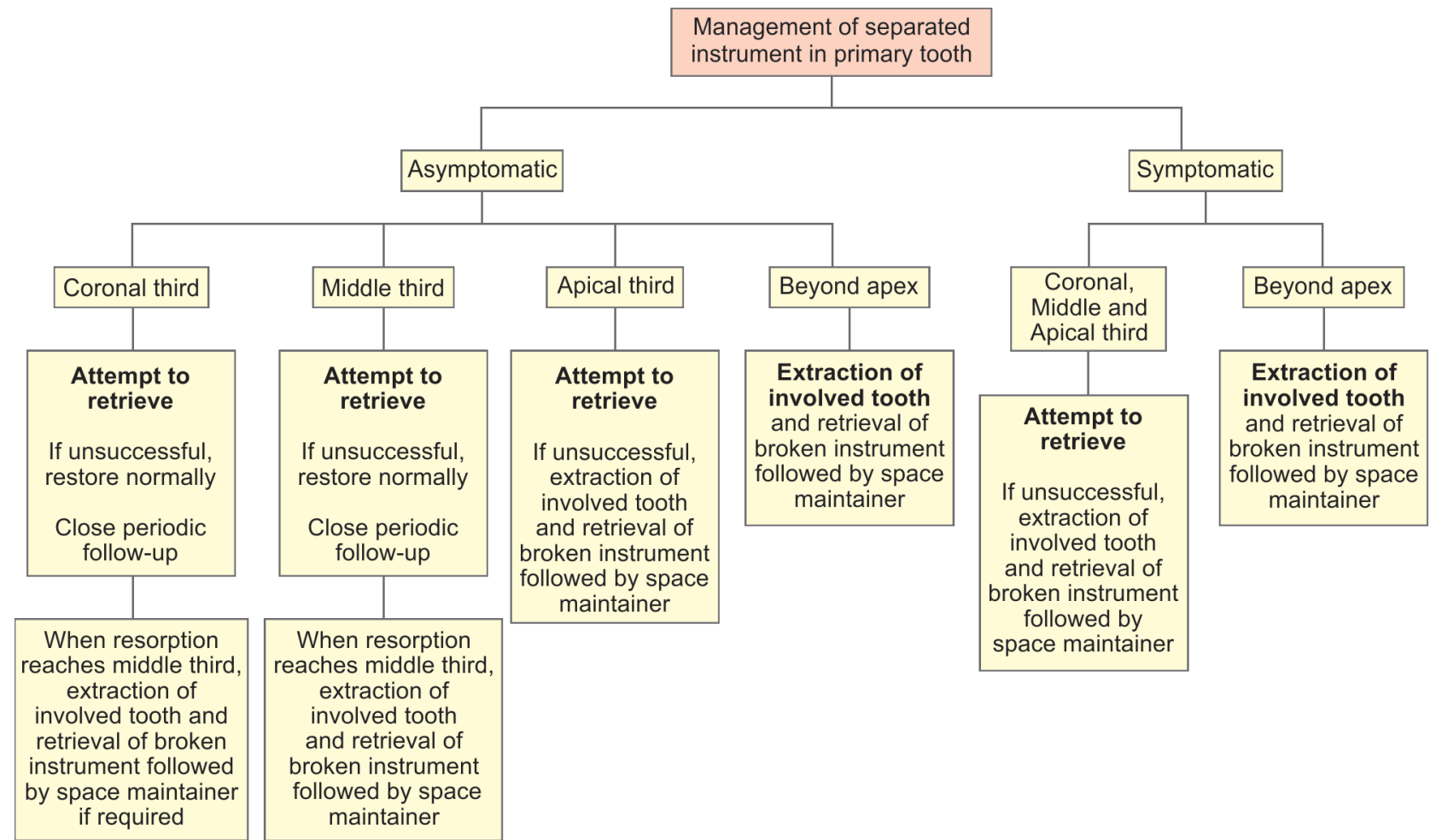

\section{References}

1. Waterhouse $P$, Whitworth J. Pediatric endodontics: endodontic treatment for the primary and young permanent dentition. In Cohen's pathways of the pulp. Kenneth Hargreaves, Stephen Cohen. 10th ed., St. Louis: Mosby; 2011. pp. 808-857.

2. Bell RA, Dean JA. Managing the developing occlusion in dentistry for the child and adolescent. Dean McDonald 9th ed., Mosby; 2011. pp. 551-552.

3. Morankar R, Goyal A. Clinical and radiographic characteristics of the primary teeth indicated for pulpectomy: a cross-sectional analysis. Int Healthc Res J 2018;2(9):223-228. DOI: 10.26440/ihrj.v2i9.182.

4. Kohli M, Kim J. A retrospective clinical study of incidence of root canal instruments separation in an endodontic graduate program. J Endod 2005;31:223.

5. Pettiette MT, Conner D. Procedural errors with the use of nickeltitanium rotary instruments in undergraduate endodontics. J Endod 2002;28:259.

6. Mothanna. A. Comparative study of root-canal shaping with stainless steel and rotary NiTi files performed by preclinical dental students. Technol Health Care 2015;23(3):257-265. DOI: 10.3233/THC-150895.

7. Parashos P, Gordon I, Messer H. Factors influencing defects of rotary nickel titanium endodontic instruments after clinical use. J Endod 2004;30(10):722-725. DOI: 10.1097/01.don.0000129963.42882.c9.

8. Sonntag D, Delschen S, Stachniss V. Root canal shaping with manual and rotary Ni-Ti files performed by students. Int Endod J 2003;36(11):715-723. DOI: 10.1046/j.1365-2591.2003.00703.x.

9. Morankar R, Goyal A, Gauba K, et al. Manual versus rotary instrumentation for primary molar pulpectomies - A 24 months

randomized clinical trial. Pediat Dent J 2018;28(2):96-102. DOI: 10.1016/j.pdj.2018.02.002.

10. Patel J, Morawala A, Talathi R, et al. Retrieval of a broken instrument from root canal in primary anterior teeth. Univ Res J Dent 2015;5(3):203-206. DOI: 10.4103/2249-9725.162799.

11. Spili $\mathrm{P}$, Parashos $\mathrm{P}$, Messer $\mathrm{HH}$. The impact of instrument fracture on outcome of endodontic treatment. J Endod 2005;31(12):845-850. DOI: 10.1097/01.don.0000164127.62864.7c.

12. Anusavice KJ. Mechanical properties of dental materials. In Phillips' Science of Dental Materials. 11th ed., Philadelphia: Saunders; 2003.

13. Cheung GSP, Peng B, Bian Z, et al. Defects in ProTaper S1 instruments after clinical use: fractographic examination. Int Endod J 2005;38(11):802-809. DOI: 10.1111/j.1365-2591.2005.01020.x.

14. Peng B, Shen Y, Cheung GSP, et al. Defects in ProTaper S1 instruments after clinical use: longitudinal examination. Int Endod J 2005;38(8):550-557. DOI: 10.1111/j.1365-2591.2005.00991.x.

15. Parashos $\mathrm{P}$, Messer $\mathrm{H}$. Rotary $\mathrm{NiTi}$ instrument fracture and its consequences. J Endod 2006;32(11):1031-1043. DOI: 10.1016/j. joen.2006.06.008.

16. Cheung GS. Instrument fracture: mechanisms, removal of fragments, and clinical outcomes. Endod Topics 2009;16(1):1-26. DOI: 10.1111/j.1601-1546.2009.00239.x.

17. Lambrianidis T. Therapeutic options for the management of fractured instruments. In: Lambrianidis T. Management of Fractured Endodontic Instruments. 1st ed., Springer, Cham 2018. 75-195.

18. Shenoy A, Mandava P, Bolla N, et al. A novel technique for removal of broken instrument from root canal in mandibular second molar. Indian J Dent Res 2014;25(1):107-110. DOI: 10.4103/0970-9290.131157. 